\title{
Utility of certain nucleophilic aromatic substitution reactions for the assay of pregabalin in capsules
}

\author{
Mohamed I Walash, Fathallah F Belal, Nahed M El-Enany ${ }^{*}$ and Mahmoud H El-Maghrabey
}

\begin{abstract}
Background: Pregabalin (PG) is an anticonvulsant, analgesic and anxiolytic drug. A survey of the literature reveals that all the reported spectrophotometric methods are either don't offer high sensitivity, need tedious extraction procedures, recommend the measurement of absorbance in the near UV region where interference most probably occurs and/or use non specific reagent that don't offer suitable linearity range.

Results: Two new sensitive and simple spectrophotometric methods were developed for determination of pregabalin (PG) in capsules. Method (I) is based on the reaction of PG with 1,2-naphthoquinone-4-sulphonate sodium (NQS), yielding an orange colored product that was measured at $473 \mathrm{~nm}$. Method (II) is based on the reaction of the drug with 2,4-dinitrofluorobenzene (DNFB) producing a yellow product measured at $373 \mathrm{~nm}$. The different experimental parameters affecting the development and stability of the reaction product in methods (I) and (II) were carefully studied and optimized. The absorbance-concentration plots were rectilinear over the concentration ranges of 2-25 and 0.5-8 $\mathrm{mg} \mathrm{mL}^{-1}$ for methods (I) and (II) respectively. The lower detection limits (LOD) were 0.15 and $0.13 \mu \mathrm{g} \mathrm{mL}^{-1}$ and the lower quantitation limits (LOQ) were 0.46 and $0.4 \mu \mathrm{g} \mathrm{mL}^{-1}$ for methods (I) and (II) respectively.

Conclusion: The developed methods were successfully applied to the analysis of the drug in its commercial capsules. The mean percentage recoveries of PG in its capsule were $99.11 \pm 0.98$ and $100.11 \pm 1.2(n=3)$. Statistical analysis of the results revealed good agreement with those given by the comparison method. Proposals of the reaction pathways were postulated.
\end{abstract}

\section{Background}

Pregabalin (PG) Figure 1, (S)-3-(amino methyl)-5-methylhexanoic acid is lipophilic GABA ( $\gamma$-aminobutyric acid) analog but it is inactive at GABAA and GABAB receptors [1]. The main site of action of PG appears to be on the $\alpha_{2} \delta$ subunit of presynaptic, voltage-dependent calcium channels that are widely distributed throughout the peripheral and central nervous system. Pregabalin binds potently to the $\alpha_{2} \delta$ subunit and modulates calcium influx at nerve terminals, and, thereby, reduces the release of several neurotransmitters, including glutamate, noradrenaline, substance $P$, serotonin and dopamine. These activities and effects result in the anticonvulsant, analgesic and anxiolytic activity exhibited by PG. Recently,

\footnotetext{
* Correspondence: nelenany1@yahoo.com

Department of Analytical Chemistry, Faculty of Pharmacy, University of Mansoura, 35516, Mansoura, Egypt
}

pregabalin has been approved by the FDA for the treatment of spinal cord injury and as the first drug indicated for the treatment of fibromyalgia [2].

Pregabalin is not yet the subject of monograph in any pharmacopeia. The literature survey revealed that few analytical methods have been published concerning the analysis of pregabalin in its dosage forms and biological matrices $v i z$, spectrophotometric [3-8], specrtofluorimetric [3,9-11] and chromatographic [12,12-26] methods. The chromatographic methods require high cost solvents in addition to elaborate treatment. On the other hand, Specrtofluorimeters are not available in many labs. Regarding spectrophotometric methods for determination of PG, some of them don't offer high sensitivity $[5,7,8]$ or need tedious extraction procedures [3]. Meanwhile, some of the spectrophotometric methods recommended the measurement of absorbance in the near UV 


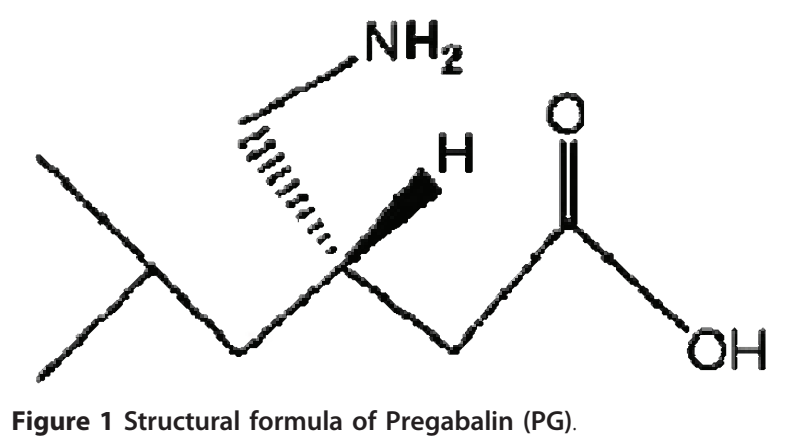

region where interference most probably occurs $[4,7]$ or use non specific reagent (Potassium iodide/potassium iodate) that don't offer suitable linearity range [6]. Therefore, our target was to develop rapid, simple, efficient and selective methods for the analysis of PG in pharmaceutical formulations. The proposed methods are based on the reaction of PG through its primary amino group either with 1,2-naphthoquinone-4-sulphonate(NQS) at $\mathrm{pH} 10.5$ or 2,4-dinitrofluorobenzene(DNFB) at $\mathrm{pH} 9.0$ to form colored reaction products peaking at 473 and $373 \mathrm{~nm}$ for the two methods, respectively.

The main advantages of the proposed methods are being simple, rapid and not require tedious extraction procedure. Compared to other reported spectrophotometric methods, the proposed methods are either more sensitive or even having comparable sensitivity.

\section{Experimental}

\section{Instruments}

- A Shimadzu UV-Visible 1601 PC Spectrophotometer (Kyoto, Japan) was used for spectrophotometric measurements ( $\mathrm{P} / \mathrm{N}$ 206-67001). The recording range was $0-1.0$

- A Consort NV P901 digital pH Meter (Belgium) calibrated with standard buffers was used for checking the $\mathrm{pH}$ of the buffer solutions used.

\section{Reagents and materials}

All the reagents used were of Analytical grade and distilled water is used throughout the work.

- Pregabalin pure sample was kindly provided by Pfizer company (Sandwich, UK) with a purity of $100.18 \%$ as determined by the comparison method.

- Lyrica ${ }^{\circledR}$ capsules batch \# 0744019 (labeled to contain $75 \mathrm{mg}$ PG each), ,product of Pfizer company, were obtained from commercial sources in the local Pharmacy.

- The 1,2-Naphthoquinone-4-sulphonate sodium (Fluka chemica, USA) solution was freshly prepared as $0.5 \%(\mathrm{w} / \mathrm{v})$ aqueous solution, for method $\mathrm{I}$.
- The 2,4-Dinitrofluorobenzene (Fluka chemica, USA) solution was freshly prepared as $0.3 \%(\mathrm{v} / \mathrm{v})$ in methanol, for method II.

- Methanol, Hydrochloric acid, Borax and Boric acid (BDH, UK).

- Borate buffer solutions (0.2 M) were prepared by mixing appropriate volumes of $0.2 \mathrm{M}$ boric acid with $0.2 \mathrm{M}$ borax and adjusting the $\mathrm{pH}$ to 10.5 and 9.0 using $\mathrm{pH}$ Meter.

\section{Standard Solutions}

Stock solution of PG was prepared by dissolving 10.0 $\mathrm{mg}$ of the drug in $100 \mathrm{~mL}$ of distilled water. This solution was further diluted with the same solvent as appropriate to obtain the working concentration range. The stock solution is stable for 7 days when kept in the refrigerator.

\section{General recommended procedures Procedures for calibration graphs}

i. Method I To a set of $10 \mathrm{~mL}$ volumetric flasks, appropriate aliquots of the standard working solution were transferred, to obtain concentrations in the range $\left(2-25 \mu \mathrm{g} \mathrm{mL}^{-1}\right)$. To each flask $1 \pm 0.5 \mathrm{~mL}$ of borate buffer solution (pH 10.5) followed by $1.0 \mathrm{~mL}$ of NQS solution $(0.5 \%)$ were added and mixed well. The solutions were heated in thermostatically controlled water bath at $55 \pm$ $5^{\circ} \mathrm{C}$ for $10 \mathrm{~min}$. The reaction was stopped by cooling under tap water, and solution was completed to the volume with distilled water. The absorbance of the resulting solution was measured at $473 \mathrm{~nm}$ against a reagent blank prepared simultaneously. The calibration graph was constructed by plotting the absorbance versus the final concentration of the drug. Alternatively, the corresponding regression equation was derived.

ii. Method II To a set of $10 \mathrm{~mL}$ volumetric flasks, appropriate aliquots of the standard working solution were transferred, to obtain concentrations in the range (0.5-8 $\left.\mu \mathrm{g} \mathrm{mL}^{-1}\right)$. To each flask $1.5 \pm 0.5 \mathrm{~mL}$ of borate buffer solution ( $\mathrm{pH} 9 \pm 0.5$ ) followed by $0.6 \pm 0.2 \mathrm{~mL}$ of DNFB solution $(0.3 \% \mathrm{v} / \mathrm{v})$ were added and mixed well. The solutions were heated in thermostatically controlled water bath at $70 \pm 10^{\circ} \mathrm{C}$ for $20 \mathrm{~min}$. The reaction was stopped by cooling under tap water, and then $0.2 \mathrm{~mL}$ of $\mathrm{HCl}$ was added and the solutions were made up to volume with distilled water. The absorbance was measured at $373 \mathrm{~nm}$ against a reagent blank. The absorbance was plotted versus the final concentration of the drug to obtain the calibration graph. Alternatively, the corresponding regression equation was derived.

\section{Assay procedure for capsules}

The contents of the ten Lyrica ${ }^{\circledR}$ capsules were emptied, weighed and then mixed well. A weighed quantity of the 
powder equivalent to $40.0 \mathrm{mg}$ PG was transferred into $100 \mathrm{~mL}$ conical flask, extracted with $3 \mathrm{X} 30 \mathrm{~mL}$ of distilled water and filtered if needed into $100 \mathrm{~mL}$ volumetric flask and the solution was completed to $100 \mathrm{~mL}$ with distilled water to prepare a stock solution of $400 \mu \mathrm{g} \mathrm{mL}^{-1}$. This solution was further diluted with the same solvent as appropriate to obtain the working concentration range. Aliquots covering the working concentration ranges $\left(8,15\right.$ and $20 \mu \mathrm{g} \mathrm{mL}^{-1}$ for Method I and 3,4 and $6 \mu \mathrm{g} \mathrm{mL}^{-1}$ for Method II) were transferred into a series of $10 \mathrm{~mL}$ volumetric flasks and the procedures under the two methods were applied. The nominal content of the capsules was determined using the corresponding regression equations or the calibration graphs.

\section{Results and Discussion}

Pregabalin has no specific absorbance since it is aliphatic compounds and devoids of any chromophores or auxchromes which are essential for light absorption. However, a spectrophotometric method was reported for the determination of PG based on the direct measurement of the absorbance at $\lambda_{\max } 210 \mathrm{~nm}$ (4). In contrast, other repots $(7,10)$ confirmed that, the drug has no specific absorbance in the UV-region. This renders its spectrophotometric determination a challenging problem. Such problem is highly aggravated when it is necessary to determine the drug especially in pharmaceutical preparations. However, aliphatic nature of PG and presence of a primary amino group which is susceptible to derivitazation with nucleophilic reagents such as NQS or DNFB initiated the present study.

1,2-naphthoquinone-4sulphonate sodium has been used as chromogenic and fluorogenic reagent for the analysis of many pharmaceutical primary and secondary amines [27-29]. However, its reaction with PG has not been yet investigated. Therefore, the present study was devoted to explore NQS as a derivatizing reagent for the development of spectrophotometric method for the determination of PG in its capsules. NQS was found to react with PG in borate buffer of $\mathrm{pH} 10.5$ yielding a highly colored orange reaction product which exhibit maximum absorbance at $473 \mathrm{~nm}$ (Figure 2).

The analytical applications of 2,4-dinitrofluorobenzene (DNFB) for the assay and characterization of specific functional groups such as primary and secondary amines, phenols, thiols and imidazoles have been reported by Connor [30,31]. In the present work DNFB reacts through a nucleophilic aromatic substitution reaction with the primary aliphatic amino group of PG in aqueous alkaline medium. The reaction between PG and DNFB is very slow at room temperature and required heating to accelerate it. A yellow colored reaction product peaking at $373 \mathrm{~nm}$ is produced (Figure 2).

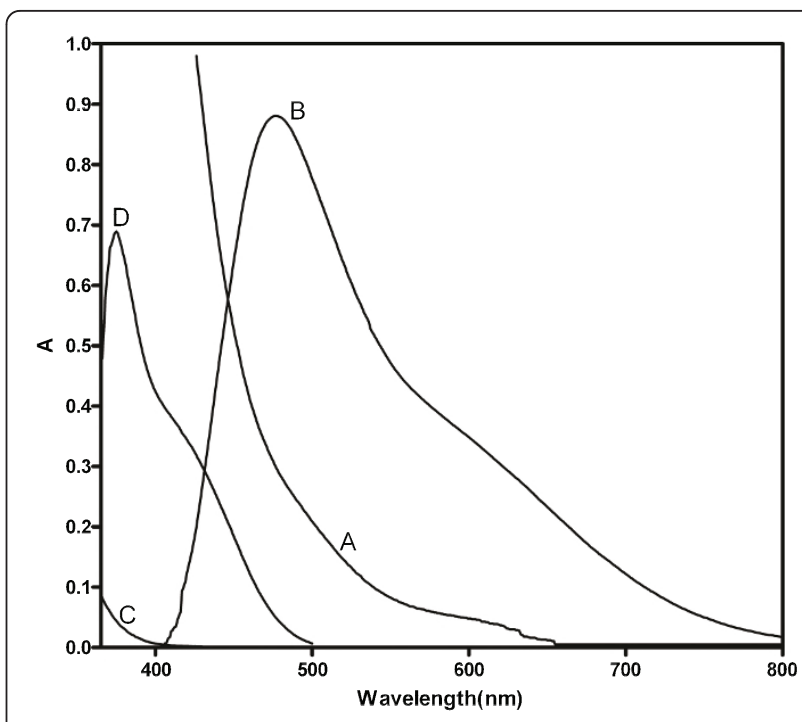

Figure 2 Absorption spectra of (a) NQS $0.5 \%(w / v)$ in water (method I). (b) PG $\left(25 \mu \mathrm{g} \mathrm{mL}^{-1}\right)$ with NQS (method I). (c) DNFB $0.3 \%(\mathrm{w} / \mathrm{v})$ in methanol (method II). (d) PG $\left(6 \mu \mathrm{g} \mathrm{mL} \mathrm{L}^{-1}\right)$ with DNFB (method II).

\section{Study of Experimental Parameters}

The experimental conditions were established by varying each in turn while keeping all others constant. These variables include; effect of $\mathrm{pH}$ and volume of buffer, effect of the concentration of reagents, effect of heating temperature and heating times, effect of diluting solvent and effect of time on stability of the reactions products.

\section{i. Effect of $\mathrm{pH}$ and volume of buffer}

The influence of $\mathrm{pH}$ on the formation of the reactions products was studied over the range of 6.0-12.0 using $0.2 \mathrm{M}$ borate buffer solution. Maximum and constant absorption intensities were achieved at $\mathrm{pH} 10.5 \pm$ 0.5 for Method I and $9.0 \pm 0.5$ for Method II. Therefore, $\mathrm{pH} 10.5$ and 9.0 were chosen as the optimum $\mathrm{pH}$ values for Methods I and II, respectively (Figure 3).

Maximum absorbance intensities were achieved using 0.8-1.5 mL or 1.0-2.0 mL of borate buffer solutions for Methods I and II, respectively (Figure 4). So that, $1.0 \mathrm{~mL}$ of borate buffer solution of $\mathrm{pH} 10.5$ and $1.5 \mathrm{~mL}$ of borate buffer solution of $\mathrm{pH} 9.0$ were chosen as the optimum buffer volumes for Methods I and II, respectively.

\section{ii. Effect of the concentration of reagents solutions}

The influence of the reagents concentration was studied using different volumes of either $0.5 \% \mathrm{w} / \mathrm{v}$ solution of NQS (Method I) or $0.3 \% \mathrm{v} / \mathrm{v}$ solution of DNFB (Method II). It was found that, increasing volumes of the reagents produced a proportional increase in the absorbance values. Maximum absorbencies were achieved using volumes of the reagents ranged from $0.7-2.0$ or $0.4-1.0 \mathrm{~mL}$ of NQS or DNFB for Methods I and II, respectively. Further increase 


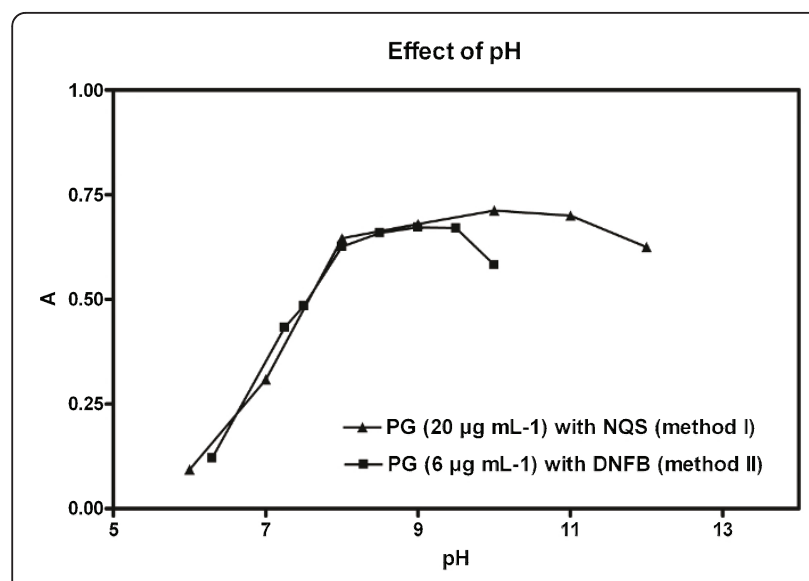

Figure 3 Effect of the $\mathrm{pH}$ of $0.2 \mathrm{M}$ borate buffer on the absorbance of the reaction product of PG of PG with NQS or DNFB.

of the reagents volume produced a gradual decrease in the absorption intensity. Therefore, $1 \mathrm{~mL}$ of $0.5 \% \mathrm{w} / \mathrm{v}$ NQS solution and $0.6 \mathrm{~mL}$ of $0.3 \% \mathrm{v} / \mathrm{v}$ DNFB solution were chosen as the optimal volumes of the reagents for Methods I and II, respectively (Figure 5). For Method II, to remove the excess DNFB reagent interference in the absorbance measurement of the reaction product, this excess was acid-hydrolyzed to colorless 2,4-dinitrophenol by adding $0.2 \mathrm{~mL}$ of $\mathrm{HCl}$ allowing the measurement of PG-DNFB derivative which remains stable.

\section{iii. Effect of temperature and heating time}

The effect of the heating temperatures on the formation of the reactions products was studied using a thermostatically controlled water bath at different temperature settings ranging from $\left(30-100{ }^{\circ} \mathrm{C}\right)$. For both methods, the results revealed that increasing the temperature resulted in an increase in the absorbance values of the reactions products. The maximum absorbance values were attained at $50-60$ and $60-80^{\circ} \mathrm{C}$ for Methods I and

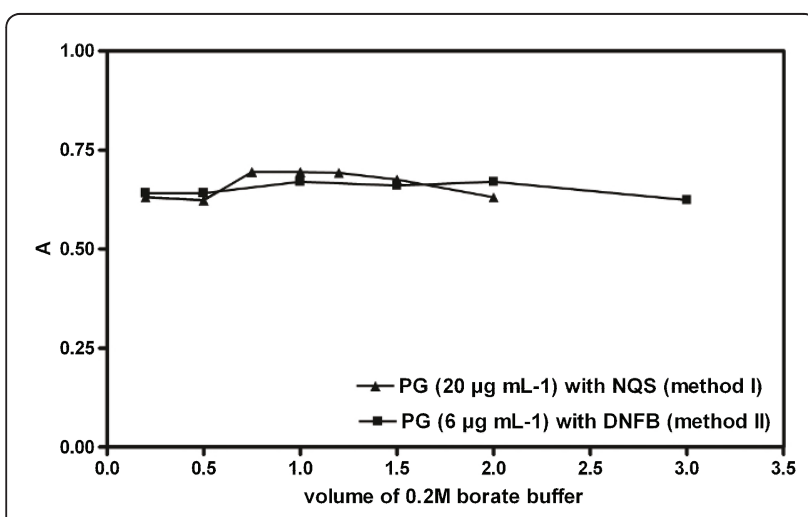

Figure 4 Effect of the volume of $0.2 \mathrm{M}$ borate buffer on the absorbance of the reaction product of PG with NQS or DNFB.

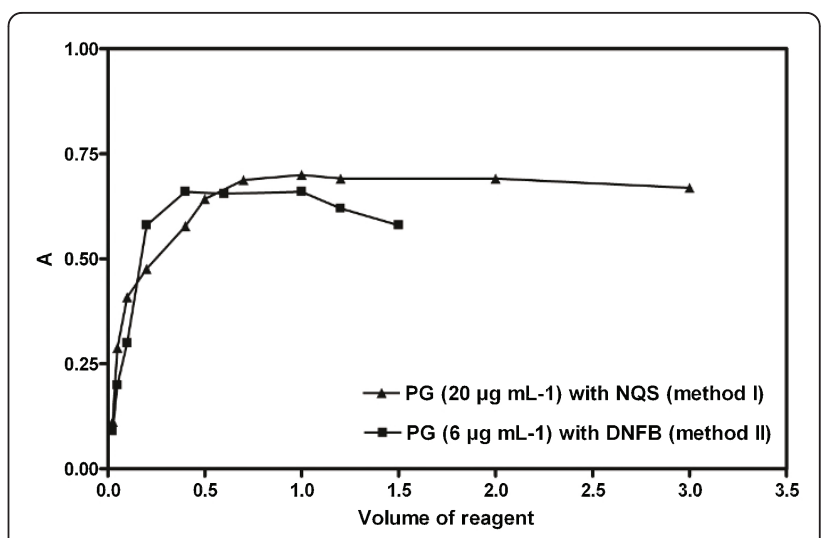

Figure 5 Effect of the volume of reagent on the absorbance of the reactions products of PG with NQS or DNFB.

II, respectively. At higher temperatures, the absorbance of the reaction product decreased gradually in case of Method I, on the other hand slight decrease of the absorbance occurred in case of Method II (Figure 6). The decrease in the absorbance was probably attributed to the instability of the PG derivatives at higher temperatures. Therefore, the studies were carried out at 55 and $70^{\circ} \mathrm{C}$ for Methods I and II, respectively.

The effect of heating times on the formation of the reactions products were investigated at different time intervals. The results revealed that, for Method I, complete reaction was achieved within $10 \mathrm{~min}$ and further increase in the reaction time did not affect the absorbance intensity (Figure 7). Regarding Method II, the reaction went to completion within $20 \mathrm{~min}$, and longer reaction times up to $25 \mathrm{~min}$ did not affect the absorbance intensity. On the other hand, heating for $30 \mathrm{~min}$ resulted in slight decrease in absorbance intensity. So that, $20 \mathrm{~min}$ was selected as the optimum reaction time for Method II (Figure 7).

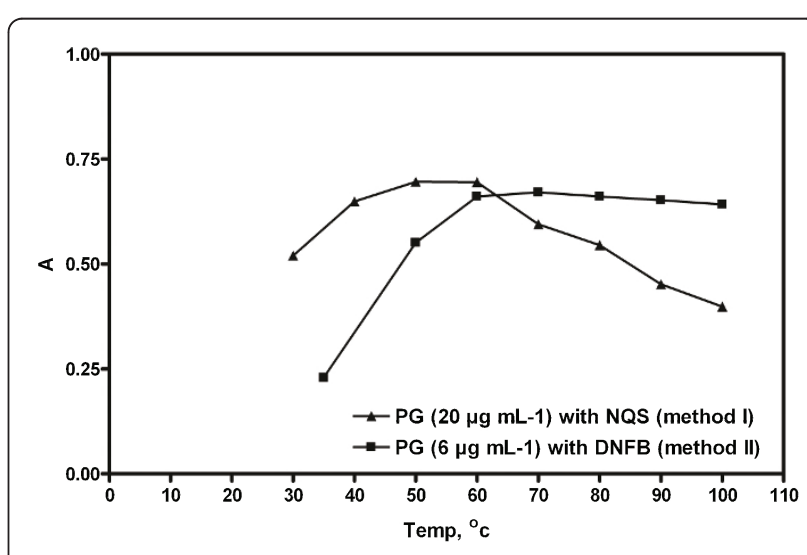

Figure 6 Effect of the temperature on the on the absorbance of the reactions products of PG with NQS or DNFB. 


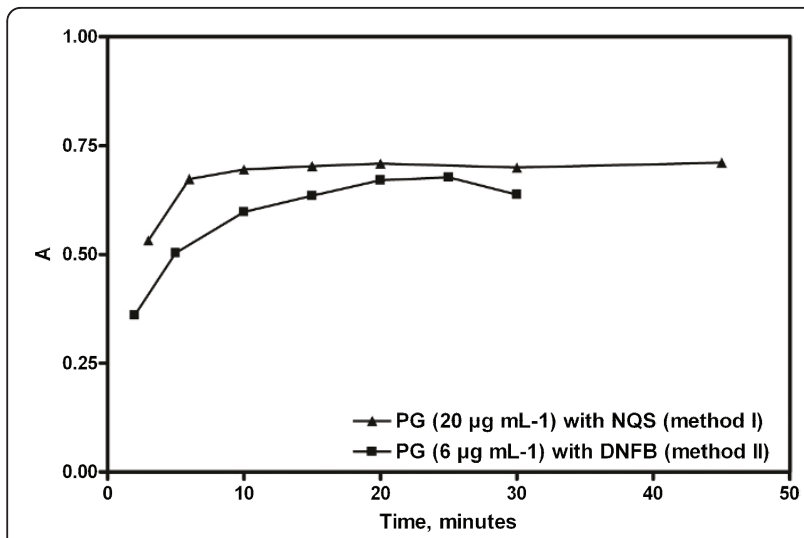

Figure 7 Effect of the heating time on the on the absorbance of the reactions products of PG with NQS or DNFB.

\section{iv. Effect of diluting solvent}

The effect of diluting solvents on the absorbance intensities of the reactions products was tested using different solvents viz water, methanol, acetone, acetonitrile and dimethylformamide. Using water as diluting solvent gave the highest absorbance values and best peaks shapes. Water was chosen finally as the best diluting solvent for the two methods.

\section{$v$. Effect of time on stability of the reactions products}

Regarding the stability of the produced derivatives, both were found to be stable at room temperature for approximately 2 hour.

\section{Validation of the proposed Methods}

The validity of the proposed methods was tested regarding linearity, specificity, accuracy, repeatability and intermediate precision according to ICH Q2(R1) recommendations [32].

\section{Linearity}

The calibration graphs obtained by plotting the values of the absorbance versus the final concentration of the drug $\left(\mu \mathrm{g} \mathrm{mL} \mathrm{m}^{-1}\right)$ were found to be rectilinear over the concentration ranges cited in Table 1 . The proposed methods were evaluated for the accuracy as percent relative error (\% Er) and the precision as percent relative standard deviation (\% RSD) (Tables 1 and 2).

The validity of the methods were proved by statistical evaluation of the regression data, regarding the standard deviation of the residuals $\left(S_{y / x}\right)$, the standard deviation of the intercept $\left(S_{a}\right)$ and standard deviation of the slope $\left(S_{b}\right)$. The results are abridged in

Table 1. The small values of the figures indicate low scattering of the points around the calibration line and high precision.

\section{Limit of quantitation and limit of detection}

The limits of quantitation (LOQ) were determined by establishing the lowest concentration that can be
Table 1 Performance data for the proposed methods

\begin{tabular}{|c|c|c|}
\hline Parameter & Method I & Method II \\
\hline Concentration range $\left(\mu \mathrm{g} \mathrm{mL} \mathrm{L}^{-1}\right)$ & $2.0-25.0$ & $0.5-8.0$ \\
\hline Limit of detection (LOD) $\left(\mu \mathrm{g} \mathrm{mL}^{-1}\right)$ & 0.15 & 0.13 \\
\hline Limit of quantification (LOQ) ( $\mu \mathrm{g} \mathrm{mL}^{-1}$ ) & 0.47 & 0.39 \\
\hline Correlation coefficient ( $r$ ) & 0.9999 & 0.9999 \\
\hline Slope & 0.0352 & 0.107 \\
\hline Intercept & -0.0116 & 0.0203 \\
\hline $\mathrm{S}_{\mathrm{y} / \mathrm{x}}$ & 0.003 & 0.005 \\
\hline $\mathrm{S}_{\mathrm{a}}$ & 0.002 & 0.004 \\
\hline $\mathrm{S}_{\mathrm{b}}$ & 0.0001 & 0.0009 \\
\hline$\%$ RSD & 1.35 & 1.10 \\
\hline \% Error & 0.51 & 0.45 \\
\hline$\varepsilon(\mathrm{l} / \mathrm{mol} . / \mathrm{cm})$. & 5604 & 17034 \\
\hline
\end{tabular}

\section{Where:}

$\mathrm{S}_{\mathrm{y} / \mathrm{x}}$ : Standard deviation of the residuals

$\mathrm{S}_{\mathrm{b}}$ : Standard deviation of the slope

$\%$ Error $=\% \mathrm{RSD} / \sqrt{ } \mathrm{n}$

$\mathrm{S}_{\mathrm{a}}$ : Standard deviation of the intercept

$\varepsilon:$ Molar absorptivity

measured according to $\mathrm{ICH}$ Q2(R1) recommendation [32] below which the calibration graph is non linear. The results are shown in Table 1 . The limits of detection (LOD) were determined by evaluating the lowest concentration of the analyte that can be readily detected. The results are also summarized in Table 1.

LOQ and LOD were calculated according to the following equations [32]:

$$
\begin{aligned}
& \mathrm{LOQ}=10 \mathrm{~S}_{\mathrm{a}} / \mathrm{b} \\
& \mathrm{LOD}=3.3 \mathrm{~S}_{\mathrm{a}} / \mathrm{b}
\end{aligned}
$$

Where $S_{a}$ is the standard deviation of the intercept of regression line, and $\mathrm{b}$ is the slope of the regression line.

\section{Accuracy}

To test the validity of the proposed methods they were applied to the determination of pure sample of PG over the concentration ranges cited in Table 1 . The results obtained were in good agreement with those obtained using the comparison method. Statistical analysis of the result obtained using student $t$-test and the variance ratio F-test [33] revealed no significance differences between the proposed and comparison methods regarding the accuracy and precision, respectively (Table 2). The spectrophotometric comparison method [3] is based on the derivitization of PG with7-chloro-4nitrobenzofurazon (NBD-Cl) [3]. The absorbance of the reaction product was measured at $460 \mathrm{~nm}$ and the concentration was rectilinear over the concentration range $0.5-7.0 \mu \mathrm{g} \mathrm{mL} \mathrm{m}^{-1}$.

\section{Precision}

i. Repeatability (intra-day) The repeatability was performed over the specific concentration range through replicate analysis of three concentrations of PG in pure 
Table 2 Application of the proposed and comparison methods to the determination of PG in pure form

\begin{tabular}{|c|c|c|c|c|c|c|c|}
\hline \multirow[t]{2}{*}{ Parameter } & \multicolumn{3}{|c|}{ Method I } & \multicolumn{3}{|c|}{ Method II } & \multirow{2}{*}{$\begin{array}{c}\text { Comparison Method [3] } \\
\% \text { Found }\end{array}$} \\
\hline & Conc. Taken $\left(\mu \mathrm{g} \mathrm{mL}^{-1}\right)$ & Conc. Found $\left(\mu \mathrm{g} \mathrm{mL}^{-1}\right)$ & $\%$ Found & Conc. Taken $\left(\mu \mathrm{g} \mathrm{mL}^{-1}\right)$ & Conc. found $\left(\mu \mathrm{g} \mathrm{mL}^{-1}\right)$ & $\%$ Found & \\
\hline & 2.00 & 2.05 & 102.50 & 0.50 & 0.50 & 100.00 & \\
\hline & 3.00 & 3.02 & 100.67 & 2.00 & 1.96 & 98.00 & 100.89 \\
\hline & 5.00 & 4.90 & 98.00 & 3.00 & 3.00 & 100.00 & 100.68 \\
\hline & 12.00 & 12.02 & 100.17 & 4.00 & 4.02 & 100.50 & 98.62 \\
\hline & 15.00 & 14.95 & 99.67 & 6.00 & 6.07 & 101.17 & 100.51 \\
\hline & 20.00 & 20.08 & 100.40 & 8.00 & 7.94 & 99.25 & \\
\hline & 25.00 & 24.93 & 99.72 & & & & \\
\hline$\overline{\mathrm{X}} \pm$ S.D. & & $100.16 \pm 1.35$ & & & $99.82 \pm 1.09$ & & $100.18 \pm 1.05$ \\
\hline $\mathrm{T}$ & & $0.02(2.26)^{\mathrm{a}}$ & & & $0.51(2.31)^{\mathrm{a}}$ & & \\
\hline$F$ & & $1.65(8.94)^{\mathrm{a}}$ & & & $1.09(9.01)^{\mathrm{a}}$ & & \\
\hline
\end{tabular}


form on three successive occasions. The results are presented in Table 3.

ii. Intermediate precision (inter-day) Intermediate precision was tested by repeated analysis of PG in pure form using the concentrations shown in Table 3 for a period of 3 successive days. The results are summarized in Table 3.

High \% recovery, low SD and low \% RSD indicate high accuracy and precision of the proposed method respectively (Table 4).

\section{Robustness of the method}

The robustness of the procedures adopted in the two proposed method was demonstrated by the constancy of the absorbance intensity with the deliberated minor changes in the experimental parameters. For Method I, the changes included the $\mathrm{pH}$ of borate buffer solution, $10.5 \pm 0.5$, the change in the volume of the buffer solution, $1.0 \pm 0.5 \mathrm{~mL}$, the change in the volume of NQS $(0.5 \% \mathrm{w} / \mathrm{v}), 1.0 \pm 0.3$, the change in the heating temperature, $55 \pm 5^{\circ} \mathrm{C}$ and the change in the heating time, $10 \pm 2 \mathrm{~min}$. Meanwhile, for method II these changes included the $\mathrm{pH}$ of borate buffer solution, $9.0 \pm 0.5$, the change in the volume of the buffer solution, $1.5 \pm 0.5 \mathrm{~mL}$, the change in the volume of DNFB $(0.3 \% \mathrm{v} / \mathrm{v}), 0.6 \pm 0.2 \mathrm{~mL}$, the change in the heating temperature, $70 \pm 10{ }^{\circ} \mathrm{C}$ and the change in the heating time, $20 \pm 2 \mathrm{~min}$. These minor changes that may take place during the experimental operation didn't affect the absorbance of the reactions products.

\section{Selectivity}

The Selectivity of the methods was investigated by observing any interference encountered from the common capsule excipients, such as lactose monohydrate, corn starch and talc. These excipients did not interfere with the proposed methods.

\section{Pharmaceutical Applications}

The proposed methods were successfully applied to the determination of the studied drug in its pharmaceutical preparations. The results obtained were statistically compared to those of the comparison method [3] using Student's $t$-test for accuracy and the variance ratio Ftest for precision respectively (Table 4). The results obtained indicate no significance difference between the proposed methods and the comparison one.

\section{Molar ratio and mechanism of the reaction}

The stoichiometry of the reactions in the two methods was studied adopting the limiting logarithmic method [34]. The two straight lines were obtained using increasing concentrations of the reagent while keeping the concentration of the drug constant and using increasing concentrations of the drug while keeping the concentration of the reagent constant. Plots of log absorbance versus $\log [\mathrm{NQS}]$ and $\log [\mathrm{PG}]$ gave two straight lines, the slopes of which were 0.93 and 1.05 for NQS and PG, respectively (Figure 8 ). Hence, It is concluded that the reaction proceeds in the ratio of $1: 1$, confirming that one molecule of the drug condenses with one molecule of NQS.

For Method II the determination of the stoichiometry of the reaction of PG and DNFB was performed similarly. Plots of log absorbance versus $\log [\mathrm{DNFB}]$ and $\log$

Table 3 Validation of the proposed methods for the determination of PG pure form

\begin{tabular}{|c|c|c|c|c|c|c|}
\hline \multirow[t]{2}{*}{ Parameter } & \multicolumn{3}{|c|}{$\begin{array}{l}\text { Method I } \\
\text { Pregabalin concentration }\left(\mu \mathrm{g} \mathrm{mL} \mathrm{L}^{-1}\right)\end{array}$} & \multicolumn{3}{|c|}{$\begin{array}{c}\text { Method II } \\
\text { Pregabalin concentration }\left(\mu \mathrm{g} \mathrm{mL} \mathrm{m}^{-1}\right)\end{array}$} \\
\hline & 8.0 & 15.0 & 20 & 2 & 4 & 6 \\
\hline \multicolumn{7}{|l|}{ Intraday } \\
\hline \multirow[t]{3}{*}{$\%$ Found } & 100.37 & 100.77 & 100.76 & 98.72 & 101.75 & 98.34 \\
\hline & 101.23 & 98.20 & 101.02 & 101.29 & 98.24 & 100.89 \\
\hline & 98.94 & 101.80 & 99.24 & 101.43 & 99.72 & 101.48 \\
\hline Mean $(\overline{\mathbf{x}})$ & 100.18 & 100.26 & 100.34 & 100.48 & 99.90 & 100.24 \\
\hline S.D. & 1.16 & 1.85 & 0.96 & 1.53 & 1.76 & 1.67 \\
\hline$\%$ RSD & 1.16 & 1.85 & 0.96 & 1.52 & 1.76 & 1.67 \\
\hline$\%$ Error & 0.67 & 1.07 & 0.55 & 0.88 & 1.02 & 0.96 \\
\hline \multicolumn{7}{|l|}{ Inter-day } \\
\hline \multirow[t]{3}{*}{$\%$ Found } & 100.47 & 99.09 & 100.32 & 99.37 & 98.90 & 102.26 \\
\hline & 99.53 & 101.48 & 99.71 & 100.63 & 101.10 & 100.75 \\
\hline & 100.78 & 100.91 & 101.16 & 98.95 & 101.10 & 99.25 \\
\hline Mean $(\overline{\mathbf{x}})$ & 100.26 & 100.49 & 100.40 & 99.65 & 100.37 & 100.75 \\
\hline S.D. & 0.65 & 1.25 & 0.73 & 0.87 & 1.27 & 1.51 \\
\hline$\%$ RSD & 0.65 & 1.24 & 0.73 & 0.88 & 1.27 & 1.49 \\
\hline$\%$ Error & 0.38 & 0.72 & 0.42 & 0.51 & 0.73 & 0.86 \\
\hline
\end{tabular}

Each result is the average of three separate determinations. 
Table 4 Application of the proposed and comparison methods to the determination of PG in capsule dosage form

\begin{tabular}{|c|c|c|c|c|c|}
\hline \multirow[t]{2}{*}{ Pharmaceutical preparation } & \multicolumn{2}{|l|}{ Method I } & \multicolumn{2}{|l|}{ Method II } & \multirow[t]{2}{*}{ Comparison method [3] } \\
\hline & Conc. taken $\left(\mu \mathrm{g} \mathrm{mL}^{-1}\right)$ & $\%$ Found & Conc. taken $\left(\mu \mathrm{g} \mathrm{mL}^{-1}\right)$ & $\%$ Found & \\
\hline Lyrica ${ }^{\circledR}$ Capsules & 8.0 & 99.91 & 3.0 & 100.45 & 101.01 \\
\hline \multirow[t]{2}{*}{$\left(^{75} \mathrm{mg} \mathrm{PG} /\right.$ capsule $^{\mathrm{b}}$} & 15.0 & 99.41 & 4.0 & 101.11 & 99.43 \\
\hline & 20.0 & 98.01 & 6.0 & 98.78 & 99.3 \\
\hline$\overline{\mathrm{X}} \pm$ S.D. & $99.11 \pm 0.98$ & & $100.11 \pm 1.20$ & & $99.91 \pm 0.95$ \\
\hline$T$ & $1.016(2.776)^{a}$ & & $0.226(2.776)^{\mathrm{a}}$ & & \\
\hline $\mathrm{F}$ & $1.070(19.00)^{\mathrm{a}}$ & & $1.591(19.00)^{\mathrm{a}}$ & & \\
\hline Nominal content of capsule $(75 \mathrm{mq})$ & $74.33 \pm 0.74$ & & $74.08 \pm 0.90$ & & \\
\hline
\end{tabular}

Each result is the average of three separate determinations.

${ }^{a}$ Values between brackets are the tabulated $t$ and $F$ values, at $p=0.05$ [33].

${ }^{b}$ Product of Pfizer (Batch No: 0744019 and Exp date: 10/2010)

[PG] gave straight lines, the values of their slopes were 0.77 for DNFB and 0.89 for PG (Figure 8). Hence, it is concluded that the reaction proceeds in the ratio of $1: 1$, confirming that one molecule of the drug condenses with one molecule of DNFB.

Based on the obtained molar ratios and in analogy to previous studies $(19,23)$ reactions pathways are postulated to proceed as shown in schemes 1 and 2, respectively.
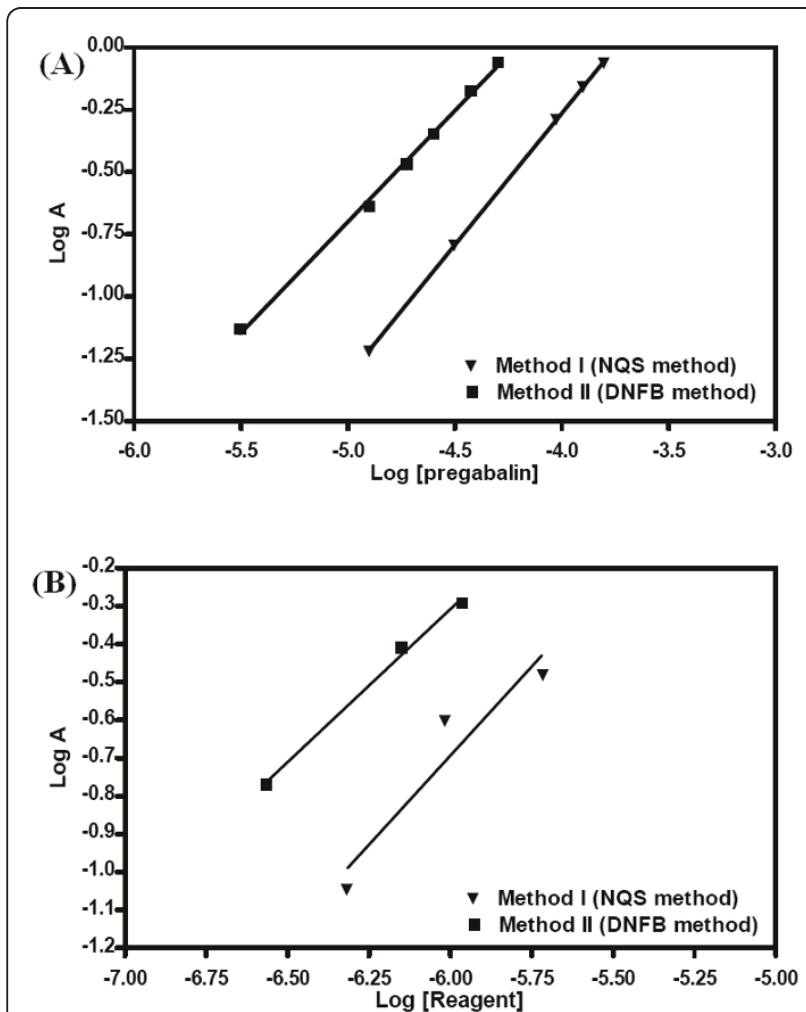

Figure 8 Limiting logarithmic plots for the molar reactivity of PG with the two proposed reagents. (A) $\log A$ vs log [reagent] with $[\mathrm{PG}$ ] kept constant; (B) $\log A$ vs $\log [\mathrm{PG}]$ with [reagent] kept constant.

\section{Conclusions}

The proposed spectrophotometric methods provided sensitive, specific and inexpensive analytical procedures for determination of the non-chromophoric drug PG either per se or in its capsule dosage forms without interference from common excipients. Moreover, the developed methods are less time-consuming and do not require elaborate treatments associated with chromatographic methods. Moreover, the reagents used are nonirritant in contrast for NBD-Cl which cause high irritant effect to the skin these attributes, in addition to the satisfactory sensitivity and reproducibility as well as the convenience and simplicity, make the two proposed methods suitable for routine analysis in quality control laboratories.

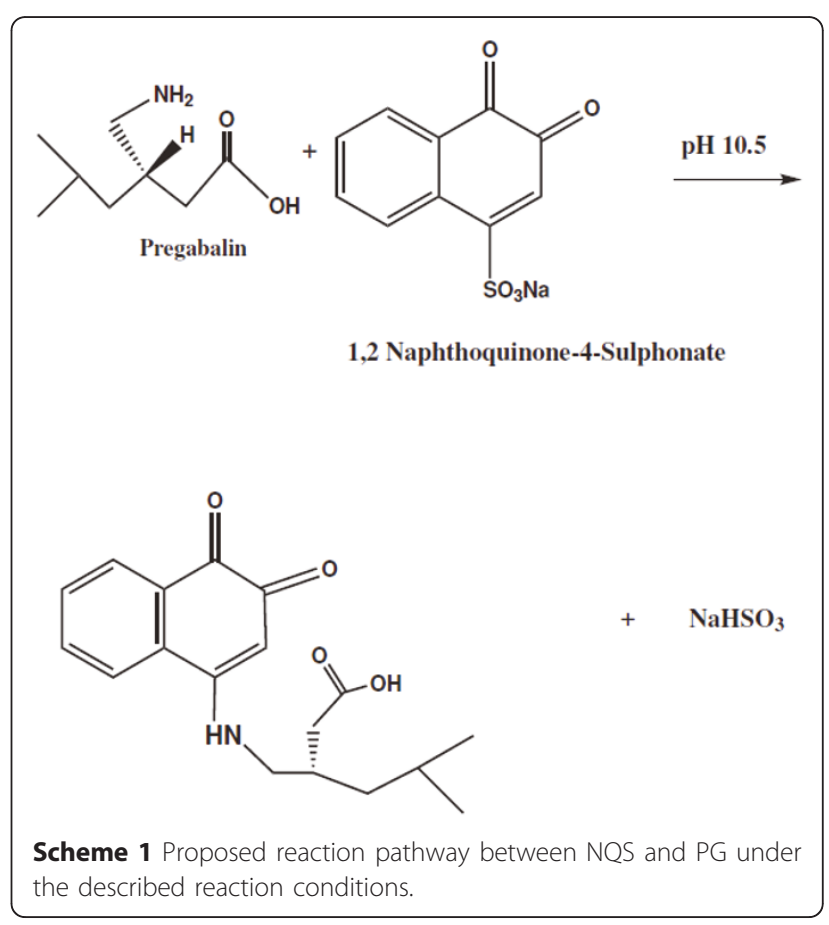


<smiles>CCC[C@H](CN)CC(=O)O</smiles>

2,4-Dinitrofluorobenzene

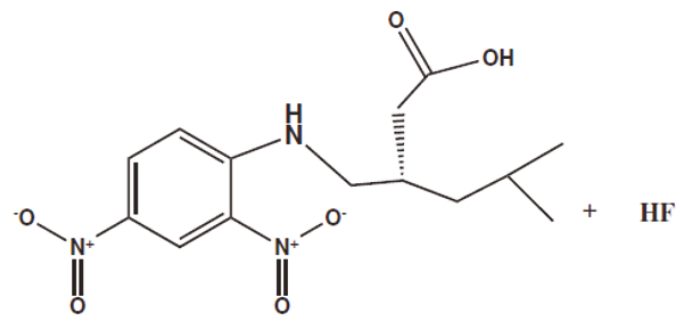

Scheme 2 Proposed reaction pathway between DNFB and PG under the described reaction conditions.

\section{Authors' contributions}

MIW designed the proposed method and analyzed the data statistically. FFB proposed, planned and supervised the whole work. NME coordinated the study and modified the text. MHE carried out the experimental work. All authors read and approved the final manuscript.

\section{Competing interests}

The author declares that they have no competing interests.

Received: 8 April 2011 Accepted: 28 June 2011 Published: 28 June 2011

\section{References}

1. Sweetman S: Martindale: The Complete Drug Reference. The Pharmaceutical Press: London; 362009.

2. Gajraj NM: Pregabalin: Its Pharmacology and Use in Pain Management. Anesth Analg 2007, 105:1805-1815.

3. Önall A, Sagirli O: Spectrophotometric and spectrofluorimetric methods for the determination of pregabalin in bulk and pharmaceutical preparation. Spectrochim Acta A 2009, 72:68-71.

4. Gujral RS, Haque SM, Shanker P: Development and validation of pregabalin in bulk, pharmaceutical formulations and in human urine samples by uv Spectrophotometry. Int I Biomed Sci 2009, 5:175-180.

5. Önal A: Development and validation of selective spectrophotometric methods for the determination of pregabalin in pharmaceutical preparation. Chin J Chem 2009, 27:781-786.

6. Gujral RS, Haque SM, Shanker P: Spectrophotometric Method for the Determination of Pregabalin in Bulk, Pharmaceutical Formulations and in Human Urine Samples. Int J Biomed Sci 2009, 5:421-427.

7. Navneet K, Karan M, Rishabh N, Kunal N, Arti T, Road F, Kalan G: A sensitive spectrophotometric method for the determination of pregabalin in pure drug and pharmaceutical formulations through benzoylation. IRJP 2010, 1:175-180

8. Salem H: Analytical Study for the Charge-Transfer Complexes of Pregabalin. E-J Chem 2009, 6:332-340.

9. Walash MI, Belal F, El-Enany N, El-Maghrabey MH: Simple and sensitive spectrofluorimetric method for the determination of pregabalin in capsules through derivatization with fluorescamine. Luminescence 2010.

10. Vovk T, Martinc B, Grabnar I: Simple high-throughput method for determination of pregabalin in pharmaceutical dosage forms using a microplate fluorescence reader. Sci Pharm 2010, 78:704.
11. Themelis DG, Tzanavaras PD, Boulimari EA: Generic automated fluorimetric assay for the quality control of gamma aminobutyric acid-analogue antiepileptic drugs using sequential injection. Anal Lett 2010, 43:905-918.

12. Vermeij TAC, Edelbroek PM: Simultaneous high-performance liquid chromatographic analysis of pregabalin, gabapentin and vigabatrin in human serum by precolumn derivatization with o-phtaldialdehyde and fluorescence detection. J Chromatogr B 2004, 810:297-303.

13. Berry $D$, Millington $C$ : Analysis of Pregabalin at Therapeutic Concentrations in Human Plasma/Serum by Reversed-Phase HPLC. Ther Drug Monit 2005, 27:451-456.

14. Jadhav AS, Pathare DP, Shingare MS: Validated enantioselective Ic method, with precolumn derivatization with marfey's reagent, for analysis of the antiepileptic drug pregabalin in bulk drug samples. Chromatographia 2007, 65:253-256.

15. Vaidya W, Yetal SM, Roy SMN, Gomes NA, Joshi SS: LC-MS-MS determination of pregabalin in human plasma. Chromatographia 2007, 66:925-928.

16. Chen $X H$, Zhang DL, Deng J, Fu XT: Determination of optical impurity of pregabalin by HPLC with pre-column chiral derivatization. J Chromatogr Sci 2008, 46:42-44.

17. Mandal U, Sarkar AK, Gowda KV, Agarwal S, Bose A, Bhaumik U, Ghosh D, Pal TK: Determination of pregabalin in human plasma using LC-MS-MS. Chromatographia 2008, 67:237-243.

18. Zhang Y, Holliman C, Tang D, Fast D, Michael SJ: Development and validation of a direct enantiomeric separation of pregabalin to support isolated perfused rat kidney studies. Chromatogr B 2008, 875:148-53.

19. Gujral RS, Haque SM, Kumar SA: A novel method for the determination of pregabalin in bulk pharmaceutical formulations and human urine samples. Afr J Pharm Pharmacol 2009, 3:327-334.

20. Nirogi R, Kandikere V, Mudigonda K, Komarneni P, Aleti R: Liquid chromatography atmospheric pressure chemical ionization tandem mass spectrometry method for the quantification of pregabalin in human plasma. J Chromatogr B 2009, 877:3899-3906.

21. Oertel R, Arenz N, Pietsch J, Kirch W: Simultaneous determination of three anticonvulsants using hydrophilic interaction LC-MS. J Sep Sci 2009, 32:238-243.

22. Douša M, Gibala P, Lemr K: Liquid chromatographic separation of pregabalin and its possible impurities with fluorescence detection after postcolumn derivatization with o-phtaldialdehyde. J Pharm Biomed Anal 2010, 53:717-722.

23. Kannapan N, Nayak SP, Venkatachalam T, Prabhakaran VJ: Analytical RPHPLC Method for Development and Validation of Pregabalin and Methylcobalamine in Combined Capsule Formulation. Appl Chem Res 2010, 13:85-89.

24. Kasawar GB, Farooqui MN: Development and validation of HPLC method for the determination of pregabalin in capsules. Indian J Pharm Sci 2010, 72:517-9.

25. Martinc B, Grabnar I, Mrhar A, Vovk T: Rapid high-performance liquid chromatography method for determination of pregabalin in a pharmaceutical dosage form following derivatization with fluorescamine. J AOAC 2010, 93:1069-1076.

26. Shah GR, Ghosh C, Thaker BTJ: Determination of pregabalin in human plasma by electrospray ionisation tandem mass spectroscopy. Adv Pharm Technol Res 2010, 1:354-357.

27. Darwish IA: Kinetic spectrophotometric methods for determination of trimetazidine dihydrochloride. Anal Chim Acta 2005, 551:222-231.

28. Li Q, Zhang H: A novel spectrophotometric method for the determination of aminophylline in pharmaceutical samples in the presence of methanol. Anal Chim Acta 2008, 551:222-231.

29. Mahmoud AM, Khalil NY, Darwish IA, Aboul-Fadl T: Selective Spectrophotometric and Spectrofluorometric Methods for the Determination of Amantadine Hydrochloride in Capsules and Plasma via Derivatization with 1,2-Naphthoquinone-4-sulphonate. Int J Anal Chem 2009, 2009:810104

30. Connor KA: Reaction Mechanisms in Organic Analytical Chemistry. Wiley: New York, U.S.A; 1973, 274

31. El-Enany N, El-Sherbiny D, Belal F: Spectrophotometric, spectrofluorometric and HPLC determination of desloratadine in dosage forms and human plasma. Chem Pharm Bull (Tokyo) 2007, 55:1662-70

32. ICH Harmonized Tripartite Guideline: Validation of Analytical Procedures. Text and Methodology, Q2(R1), Current Step 4 Version, Parent Guidelines on 
Methodology 2005 [http://www.bioforum.org.il/Uploads/Editor/karen/

q2_r1_step4.pdf].

33. Miller JN, Miller JC: Statistics and chemometrics for analytical chemistry.

Prentice Hall: England; 5 2005, 256.

34. Rose J: Advanced physico-chemical experiments. Pitman: London, England; 1964.

doi:10.1186/1752-153X-5-36

Cite this article as: Walash et al:: Utility of certain nucleophilic aromatic substitution reactions for the assay of pregabalin in capsules. Chemistry Central Journal 2011 5:36.

\footnotetext{
Publish with ChemistryCentral and every scientist can read your work free of charge

"Open access provides opportunities to our colleagues in other parts of the globe, by allowing anyone to view the content free of charge." W. Jeffery Hurst, The Hershey Company.

- available free of charge to the entire scientific community

- peer reviewed and published immediately upon acceptance

- cited in PubMed and archived on PubMed Central

- yours - you keep the copyright

Submit your manuscript here: 